\title{
Advantages and Disadvantages of Online Teaching and Learning Business English Based on a Survey Conducted among SBA Students
}

\author{
Krystyna Heinz, Martina Chylková
}

\begin{abstract}
The article presents results of a survey conducted using the method of the Semantic Differential among students of Business English at School of Business Administration in Karviná, Silesian University in Opava, related to respondents' attitudes to advantages and disadvantages of online learning during the first part of the Coronavirus pandemic. Students' answers have shown the lack of unanimous responses, which indicates the fact that they were not able to evaluate the situation in a distinct way placing their answers mainly in the middle of the offered spectrum. The authors of the article especially appreciate the data collected in the two last questions as they can contribute to optimization of online learning and teaching in the future.
\end{abstract}

\section{Introduction}

To be online or not to be online. That was not the question. Our education system was shifted online almost in a day. Both students and teachers appeared to find themselves in a completely new situation having to cope with new challenges and situations and to adapt to the elearning environment very quickly. It was not easy to adjust to this new form of learning and teaching. An important sign which definitely influenced the attitudes to the process of transition from offline to online forms should be taken into consideration by both sides who needed to deal with the pandemic and its consequences and therefore the transition was not voluntary, there was no choice.

Nowadays, especially in the coronavirus crisis, Information Communication Technologies (ICT) play a significant role in designing a new and improved model of teaching and learning. A great number of studies have been conducted to examine the advantages of integrating ICT in language education in general and English as a Second Language teaching and learning in particular. As Yunus et al. (2013) state there is a need for more studies on the advantages and disadvantages of using IT in language education.

The article focuses on identifying both advantages and disadvantages of using ICT as seen by students, specifically the Microsoft TEAMS Programme used mostly for a synchronous learning and the Information System (IS) applied to an asynchronous one, in teaching and learning Business English and aims to list suggestions related to better understading and using the potential of ICT and to imple- 
ment some new pedagogical approaches into teaching for the future to increase the learning and teaching potentials.

The goal of the presented survey was to find out students'attitudes toward learning and teaching online, use their positive features and avoid the negative ones if the coronavirus crisis repeats in the future. The authors used a questionnaire distributed to the students of the second and final parts of the Business English curriculum at School of Business Administration in Karviná, Silesian University in Opava, taught in a scheduled form in the second semester of the lockdown. The data was collected in the first quarter of the year 2021 both from full-time and part-time students.

However, the revealed disadvantages of using ICT can involve difficulties in classroom control, students' being often distracted and unwilling to cooperate.

\section{Looking back}

Students' and teachers' attitudes to using IT have been a goal of studies for a lot of years. A study carried out by Blachowicz et al. (2009) was based on observing the technology in use by the students, following the classroom dynamics and teacher choices, and looking into students' and teachers' perceptions and beliefs about technology. It also emphasized an interesting aspect related to less time devoted to teachers' management of courses using IT, giving them more time to focus on other aspects of instructional time. Moreover, the learning technology allowed students to develop independent work habits and to build both their skills and confidence about using technology. Analyses of student performance also suggest that student performance improved in the classes in which the technology was used.

In Marwan and Sweeney's opinion (2010), the twenty-first century students require different treatment in terms of teachers' methods of teaching. The current generation of students are different in terms of their creativity and self-discovery skills, being able to do many things on their own including searching for educational related materials online.

Comas-Quinn (2011) deals with so called blended learning and a key role played by teachers, indicating how important the transition from their traditional faceto-face classroom roles to the wider more complex role that blended learning requires can be. It also presents and discusses findings from a small-scale evaluation study which compared quantitative and qualitative data gathered through a survey and a small number of interviews. The revealed negative attitudes reflected in teachers' opinions are according to the author related to the transformation of teachers' identity that results from moving from traditional classroom-based teaching to online teaching. 
Arkorful and Abaidoo (2015) claim that teaching and learning online as a method of education shows both advantages ansd disadvantages. First of all, it makes the learners undergo contemplation, remoteness, as well as lack of interaction or relation. It therefore requires a very strong motivation and time management skills in order to reduce such effects. Therefore, in terms of clarifications, explanations, and interpretations, teaching and learning online can be less effective than traditional methods. On the contrary, environment for online teaching and learning is tolerant, offering an equal access to information irrespective of the locations of the users, their ages, ethnic origins, and races. Moreover, the online settings can also encourage learners to depend on themselves as teachers are no longer the solitary source of knowledge, becoming advisors and guides.

Tirziu and Vrabie (2016) deal with the Finnish online environment introducing the term of the NET Generation. They state that the NET Generation students are not so keen on using traditional methods of learning, demanding to receive more technological challenges and flexibility. They express an opinion that if tertiary institutions do not implement online learning, they will become unattractive for today's learners. Therefore, it is inevitable to stimulate virtual spaces to share information, collaborate, explore and also form proper communities to belong to and to help people to have a creative and innovative thinking.

As COVID-19 affected institutions of higher education all over the the world, thousands of schools turned towards remote learning, a lot of researchers including for example Toquero (2020) encouraged teachers to document the effects of the present pandemic on educational systems. Therefore, tertiary institutions are required to adjust their pedagogical practices to the learning needs of the students studying from their homes.

Lockee (2020) refers to the change related to online education during the Covid time as to the forced shift because both educators and students across all levels of education had to adapt to virtual courses quickly. She also focuses on changes in learning outcomes, i.e. altering unsuitable assignments and measuring students' performance, and recommends for example interactive discussions, student-led teaching, the use of games to increase motivation and attention, which present the meaningful application of newly learned skills and knowledge.

Rawashdeh, Syam and Serhan (2020) conducted the research studies related to the following advantages of online learning: flexibility of time and place, selftailored learning, the ability of students to learn according to their own pace and in the comfort of their environment, an increased access to materials, efficiency, and ability to participate in a relatively stress free environment. On the other hand, research studies reported the following disadvantages of online learning as perceived by students: lack of self-discipline, inability to manage time effectively, technological difficulties, lack of face-to-face interaction with instructor and class- 
mates, more work than face-to-face classes, and lack of sufficient time to complete assignments. Even with these disadvantages, the majority of surveyed students indicated their satisfaction with the online classes.

Dhawan (2020) names other pros of online learning including the use of prerecorded lectures, he also explains the positive feature of scheduled lessons: interaction with students and among students, which is crucial for language education. On the contrary, he states some of the cons, namely lack of e-learning competencies, downloading errors, issues with installation, login problems, and problems with audio and video, difficulties in understanding instructional goals, balancing work, family and social lives, etc.

\section{Evaluation of the students' answers to the selected questions}

The questionnaire was based on the method of the semantic differential which measures people's reactions to stimulus words and concepts in terms of ratings on bipolar scales defined with contrasting adjectives or nouns at each end. The method belongs to psycho-semantic ones (Miovský 2006, p. 193) investigating individuals'attitudes in the system of positive and negative evaluation being based on locating a concept on a scale in the multidimensional semantic space.

We have decided for this method because the semantic differential is able to affect various dimensions of students' attitudes related to cognitive, emotional, and conative characteristics. It is obvious that the semantic differential method goes deeper than usual questionnaire methods because respondents are not familiar with the level of data processing, and thus, they cannot consciously influence the results related to responses they provide.

The cognitive component of the attitude reveals the evaluation of the investigation subject. The emotional component of the attitude refers to to the investigation object. The conative component of the attitude is mainly important in the research because it refers to possible actions towards the object.

The questionnaire was delivered online through Google Forms in the first quarter of the year 2021. The link for the survey was shared via the IS. It was available both for full-time and part-time students, however, no attention was given to the comparison of the mentioned two groups of students. It comprised 12 questions raised by the authors who had been teaching English courses via TEAMS and had been able to see both advantages and disadvantages of online learning and teaching. Therefore, it was very interesting and useful to acquire information related to students' attitudes toward online learning in seven selected answers which are the object of the presented analysis. 93 questionnaires have been collected. 
1 I am a full-time student/I am a part-time student:

I AM A PART-TIME STUDENT.

The questions have been answered by 93 students $(51.6 \%)-48$ of them belong to full-time students and $46(49.5 \%)$ to part-time students, which means that slightly more full-time students responded to the questions.

2 Online learning is for me generally:

\begin{tabular}{|l|l|l|l|l|l|l|l|l|}
\hline more efficient & 1 & 2 & 3 & 4 & 5 & 6 & 7 & less efficient \\
\hline
\end{tabular}

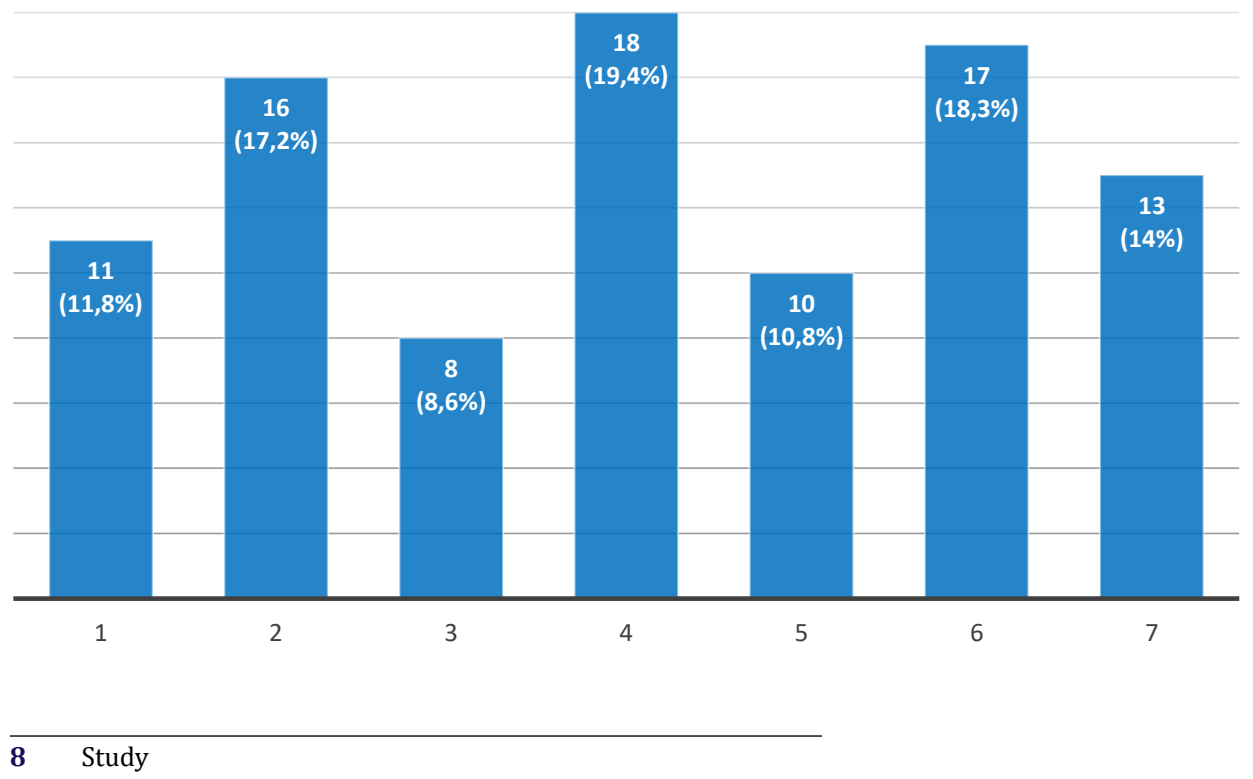


Students' answers to question 2 related to the benefit of online learning are generally distributed on both sides of the spectrum, with the highest number of answers concentrating in the scale position $4(18,19.4 \%)$. The other answers give evidence that for a slightly higher number of students learning online is less efficient $(40,43 \%)$ than face-to-face lessons $(35,37.6 \%)$, which means that the respondents have not been able to see distinct advantages or disadvantages of online learning.

3 Online learning English appears for me to be:

\begin{tabular}{|l|l|l|l|l|l|l|l|l|}
\hline more difficult & 1 & 2 & 3 & 4 & 5 & 6 & 7 & easier \\
\hline
\end{tabular}

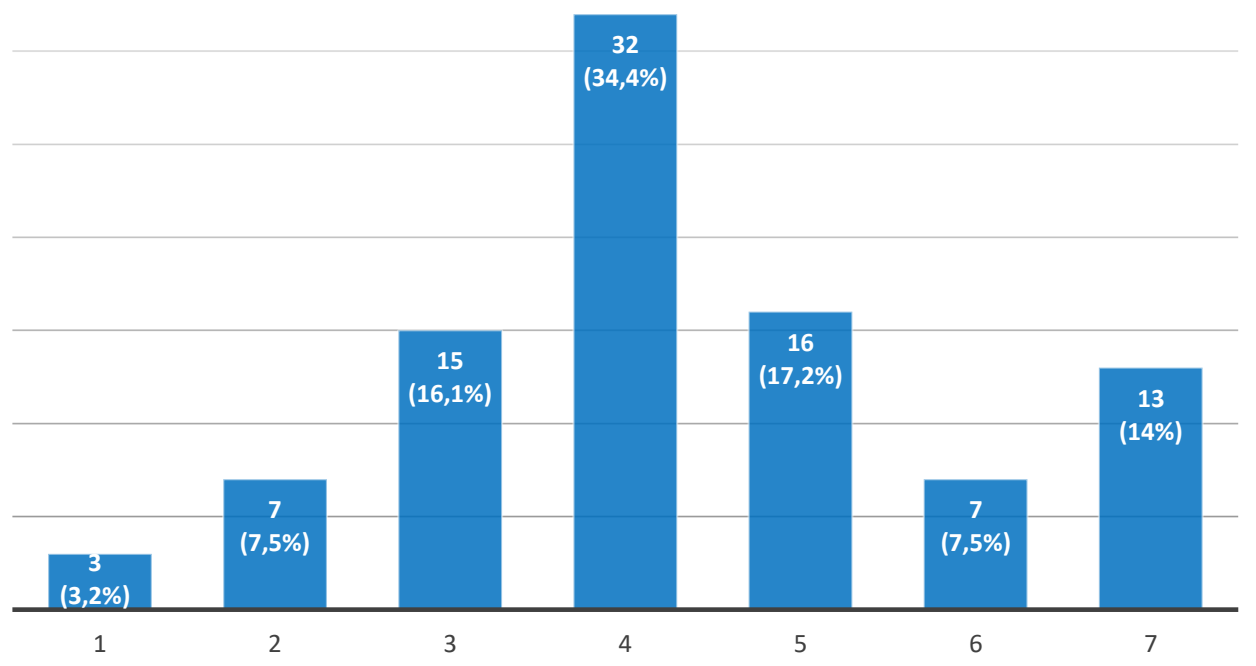

Students' responses connected to the difficulty of online learning are mostly evenly distributed in the offered spectrum with the exception of the scale position 7, where $13(14 \%)$ students have stated that online learning is definitely less difficult for them. The highest number of respondents again have placed their answers in the middle of the spectrum $(32,34.4 \%)$, which presumably means that their approach to online learning is indifferent. 
4 I always:

\begin{tabular}{|l|l|l|l|l|l|l|l|l|}
\hline $\begin{array}{l}\text { participate in } \\
\text { English lessons in } \\
\text { an active way }\end{array}$ & 1 & 2 & 3 & 4 & 5 & 6 & 7 & $\begin{array}{l}\text { participate in } \\
\text { English lessons in } \\
\text { a passive way }\end{array}$ \\
\hline
\end{tabular}

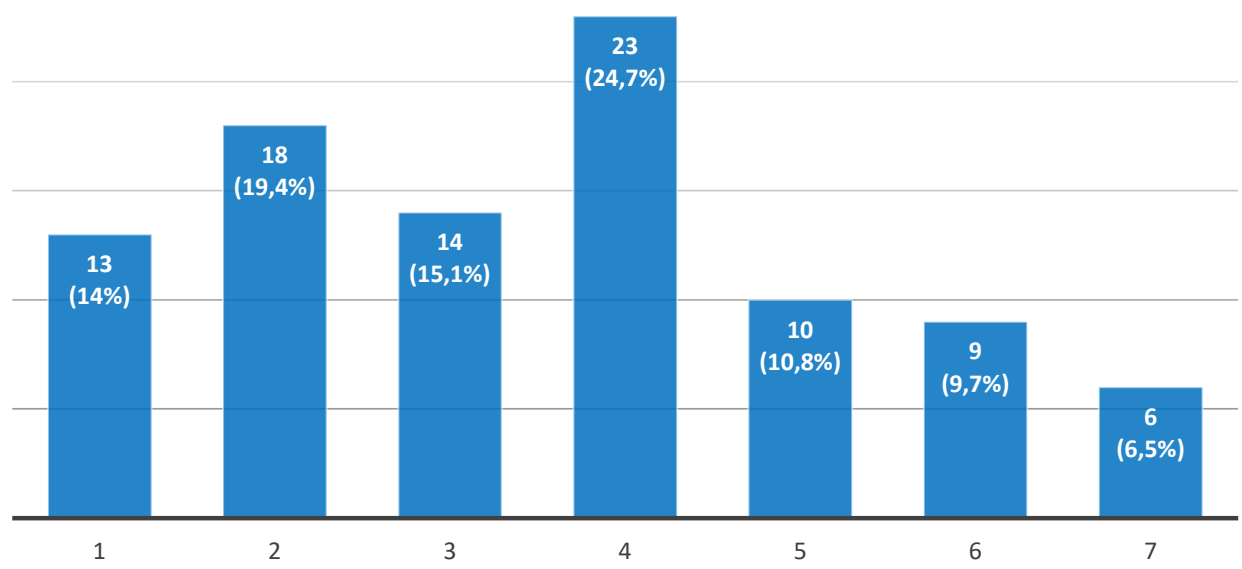

The chart number 4 shows students' attitudes to their active or passive way of participating in online learning. The highest number of answers has been again placed in the scale position $4(23,24.7 \%)$, but the other answers are concentrated in the left side of the spectrum $(45,48 \%)$, which shows students' opinions related to their active participation in online learning. Only a low number of respondents $(25,27 \%)$ think that they participate in online learning in a less active way. 
5 Having more time during the lockdown I am:

\begin{tabular}{|l|l|l|l|l|l|l|l|l|}
\hline $\begin{array}{l}\text { more motivated to } \\
\text { search for other } \\
\text { possibilities to } \\
\text { improve my English }\end{array}$ & 1 & 2 & 3 & 4 & 5 & 6 & 7 & $\begin{array}{l}\text { less motivated to } \\
\text { search for other } \\
\text { possibilities to } \\
\text { improve my English }\end{array}$ \\
\hline
\end{tabular}

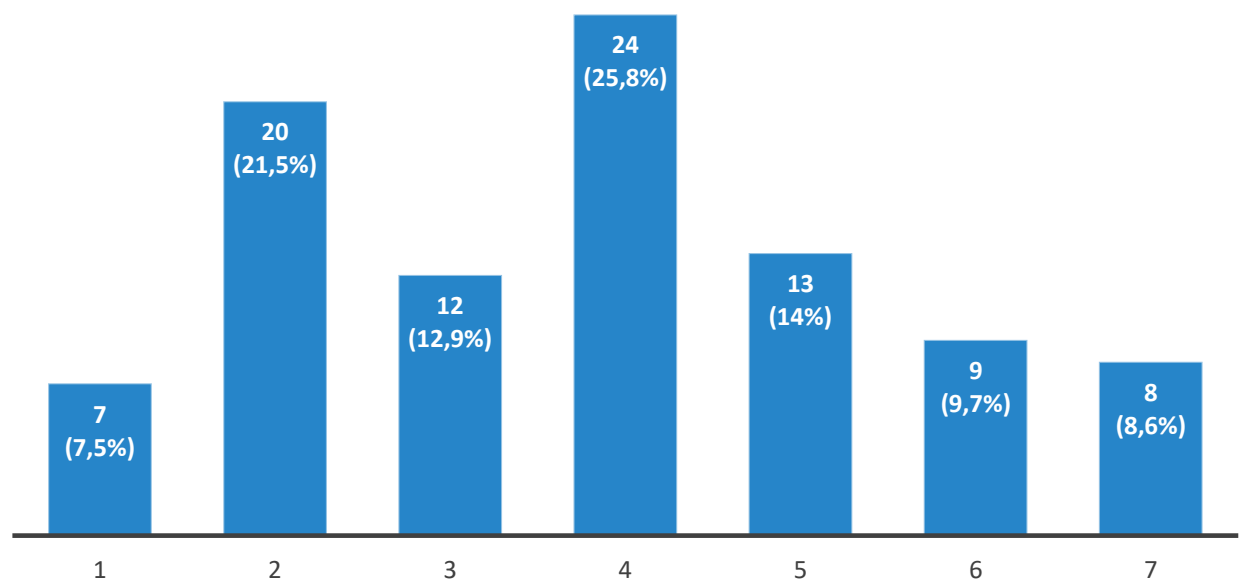

The chart showing answers to question 5 indicates more replies in the left side of the spectrum (39.42\%) while the right side of the spectrum presents only 30 answers $(31.3 \%)$ of the total number of students' answers. The highest number of answers is placed in position $4(24,25.8 \%)$, which proves that students are not sure about their answers, but generally they seem to get more motivated to improve their English during lockdown. 


\begin{tabular}{|l|l|l|l|l|l|l|l|l|}
\hline face-to-face lessons & 1 & 2 & 3 & 4 & 5 & 6 & 7 & online lessons \\
\hline
\end{tabular}

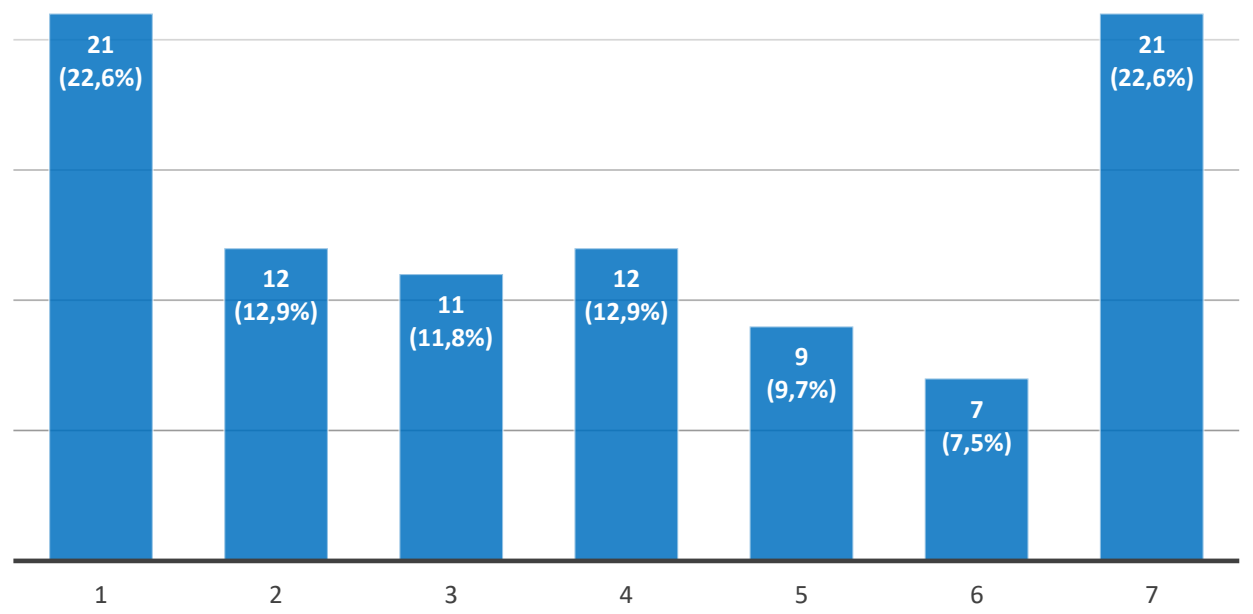

The chart presenting students' preferences related to face-to-face or online lessons indicates that students have shown their distinct attitudes to the question as high numbers of replies are placed in the opposite positions of the spectrum 1and $7(42,45.2 \%)$. However, in total, fewer respondents prefer online learning in positions 5 and $6(16,17.2 \%)$ while positions 2 and 3 on the opposite side show the number $23(34.7 \%)$. Only 12 answers are placed in the middle of the scale, which means that students have developed clear opinions about online learning. 
7 I find the lack of interaction in English learning:

\begin{tabular}{|l|l|l|l|l|l|l|l|l|}
\hline more important & 1 & 2 & 3 & 4 & 5 & 6 & 7 & less important \\
\hline
\end{tabular}

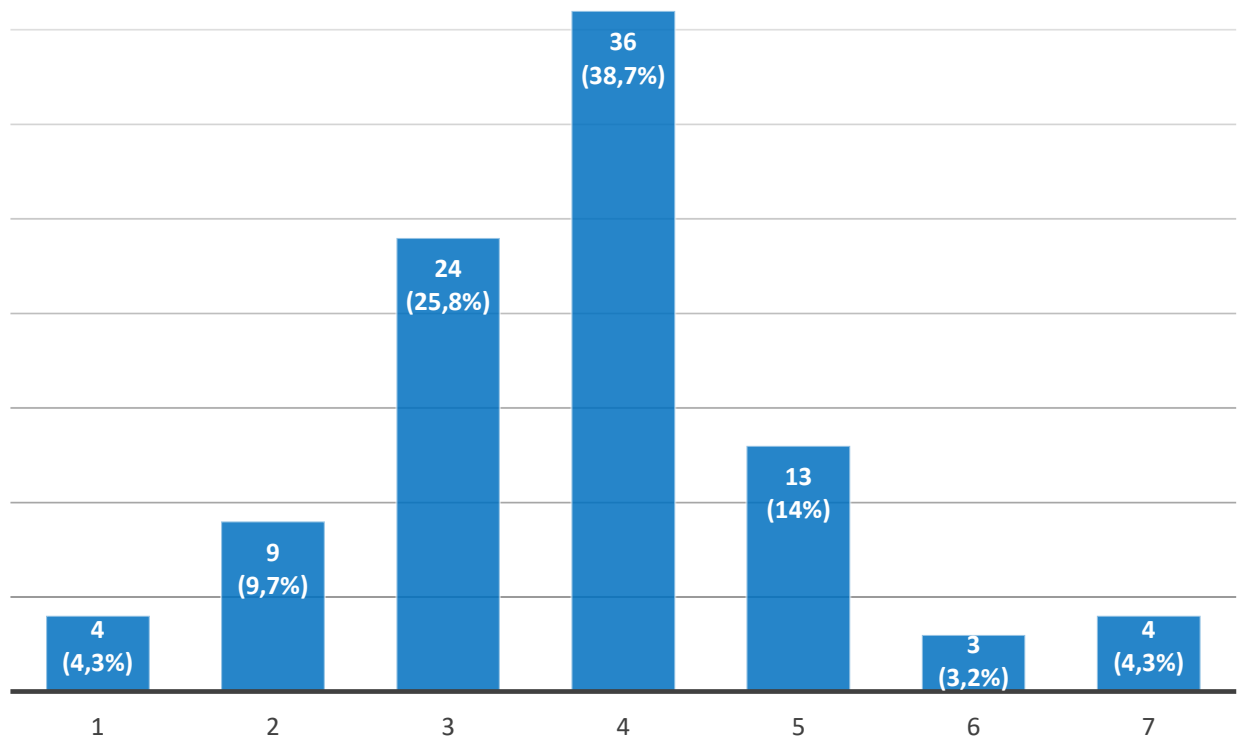

Answers to question 7 indicate that students definitely find the lack of interaction difficult as the left side of the spectrum shows a higher number of answers (37, $39.8 \%$ ) while the right side of the spectrum involves only 20 answers $(21.5 \%)$. The highest number of replies has been placed in position $4(36,38.7 \%)$, which means that for a third of respondents the form of study is not important, but more students prefer face-to-face learning.

\section{List 5 positive points about online learning:}

Students have generated a lot of ideas related to positive points about online learning, however, numerous ones have approached the question in a general way, i.e. referring to online learning generally- not only in the context of English learning. Students' responses can be divided into 5 following groups:

1. Online learning contributes to saving time and expenses on travelling, allowing students to be more productive and more motivated and leads to better time management. 
2. In students' opinions, learning from home enables to be less exposed to stressful situations during the lessons, which is more comfortable for shy students as students seem to be more anonymous.

3. Respondents highly appreciate the possibility to watch recorded materials as they can use them any time according to their needs.

4. A certain number of respondents have stated that online learning contributes to developing their IT knowledge.

5. For some students it is important that learning online means reduced risk of being infected with the Covid 19.

Students' answers also involved specific opinions related to English learning as for example

- easier working with vocabulary

- eating during lessons

- cheating

- having more productive interactions with a teacher

- better conditions for listening skills

- more interactive tools, etc.

Below, it is possible to find some selected students' quotations after having been corrected in terms of the English language:

I can stay at home, I can wake up later, I can use my PC for things I would have to do at school classes normally. It's easier for me to be online.

I can be more efficient, more motivated to search for other possibilities to improve my English.

No way to school, we are home, more time for presentations and seminal works, we are protected from the Covid, all materials are online for students.

I can take part in all the lessons.

I have only 3 positive points about online learning: more time for my activities, I spend more time with my family, I can make money.

\section{List 5 negative points about online learning:}

In comparison with the positive points concerning online learning, 13 respondents (about 14\%) have clearly stated that they cannot see any negatives about online learning. The other students' answers concentrate around the following topics:

1. Lack of direct contact and interaction between students and teachers, but also among students. 
2. Slow feedback and misunderstandings during lessons because of lag in reaction leading to less motivation and concentration.

3. Problems with IT related to bad connection and spending a lot of time in front of the computer.

4. Absence from the classes - students are reluctant to spend 90 minutes online.

5. Disturbing surroundings at home related to the family, children's education, working online, and other duties.

6. Being nervous during long tests online.

Respondents have also mentioned other specific issues, concerning teachers especially, for example:

- teachers not being able to use TEAMS

- teachers do not remember students

- teachers do not answer emails

- online lessons being boring

- losing knowledge

- difficulties with getting equipment for online lessons

The following quotations from students' answers illustrate some of the mentioned above opinions. The statements have been corrected in terms of the English language:

Misunderstandings, reluctance to spend 90 minutes online in front of the PC, mistakes in personal contact not only with the teacher but also with other students.

I don't improve my English, I am less motivated, there is a small number of people present at lessons.

Almost no contact with teachers, almost no contact with students, insufficient explanation of the topic, long feedback from some teachers.

I'm more nervous during written or oral tests than I am at school (countdown timer, the inability to return to the answers or see the whole test).

Internet connection is sometimes weak (the whole family online at the same time), the whole impact of the crisis (taking care of children and their education, cooking, cleaning, working from home office and doing loads of seminar works and home works not only for English lessons at the same time is extremely demanding).

\section{Discussion and conclusion}

The goal of the presented survey was to find out students'attitudes toward learning and teaching online, use their positive features and avoid the negative ones if 
the coronavirus crisis repeats in the future. This could contribute to the optimization of online learning and teaching in some areas and can be incorporated into the Interactive Syllabus that is available for all the students from the Information System of School of Business Administration.

It is obvious that the students' reactions to the concepts on the opposite poles of the semantic differential spectrum could be different nowadays as the data was collected in the middle of the pandemic and the respondents could have acquired different points of view in the last online learning period. However, the structure of responses shows that most answers have been placed in the middle of the spectrum (with the exception of the question 6), which gives evidence that the respondents are not able to provide a clear answer as they have not developed a distinct opinion or they tend to place it in the middle of the spectrum.

In question 6, concerning students' preferences related to face-to-face or online lessons, answers were skewed toward the lower and higher ends of the scale (17 ), indicating that they hold strong opinions on the matter.

Only 12 answers in the mentioned question are placed in the middle of the scale, which means that students have developed clear opinions about online learning.

The most significant source of information including recommendation and inspiration for the authors related to advantages and disadvantages of online learning can be found in the questions 12 and 13 of the questionnaire as the students could list their opinions about their productivity and reluctance, motivation and the lack of motivation, being or not being anonymous, being forced to develop their IT knowledge, and occurring in the situation when the risk of being infected with the Covid 19 is reduced. Important information is related to having a better contact with a teacher, better conditions for developing listening skills, more interactive tools, and easier working with vocabulary. Some students' opinions are unexpected stating the possibility of eating during lessons and cheating as an advantage. Majority of the listed opinions correspond to the mentioned outcomes of the previous research.

Disadvantages involve the lack of direct contact and interaction between students and teachers, but mainly among students, delays in students' and teachers' reactions and misunderstandings during lessons because of the lag leading to less motivation and concentration, difficulties with the connection, reluctance with being present at the lesson, and disturbing surroundings. Additional information is connected to the facts related to losing knowledge and difficulties with getting equipment for online lessons.

In conclusion, it is necessary to state that the surveyed students' preferences for face-to-face or online lessons show that a higher number of students prefer 
face-to-face English lessons. This fact is indicated especially in chart 6, in which fewer students' answers show a preference for online learning. The authors are aware that language teaching and learning have their specifics in terms of the inevitable interaction between students and teachers; therefore, the same questionnaire survey conducted in a different course may yield different results. This survey has been limited to evaluating only a few of the questions contained in the questionnaire. We intend to continue exploring this topic, hopefully contributing to a deeper understanding of students' opinions related to online learning.

\section{References}

Arkorful, V. \& AbAidoo, N. (2015). The role of e-learning, advantages and disadvantages of its adoption in higher education. In: International Journal of Instructional Technology and Distance Learning. itdl.org

Blachowicz, C., Bates, A., Berne, J., Bridgman, T., Chaney, J. \& Perney, J. (2009). Technology and At-Risk Young Readers and Their Classrooms. Reading Psychology, 30, 387-411. DOI 10.1080/ 02702710902733576

ComAs-QuinN, A. (2011). Learning to teach online or learning to become an online teacher: An exploration of teachers' experiences in a blended learning course. ReCALL, 23(3), 218-232. DOI: 10.1017/S0958344011000152

LockeE, B. B. (2021). Online education in the post-COVID era. Nature Electronics, 4(1), 5-6.

MARWAN, A, \& SwEEnEY, T. (2010). Teachers' perceptions of educational technology integration in an Indonesian polytechnic, Asia Pacific Journal of Education, 30(4), 463-476. DOI: 10.1080/ 02188791.2010 .519554

MiovskÝ, M. (2006). Kvalitativní přístup a metody v psychologickém výzkumu. Praha: Grada.

RAWASHDEH, A., SYAM, M., \& SERHAN, D. (2020). Transitioning from face-to-face to online learning: Students' achievements and perceptions of learning Calculus during COVID-19 pandemic. In I. SAHIN \& M. SHELLEY (Eds.), Educational practices during the COVID-19 viral outbreak: International perspectives (pp. 221-238). Retrieved from https://www.istes.org/

transitioning-from-face-to-face-to-online-learning-students-achievements-and-perceptions-oflearning-calculus-during-covid-19-pandemic-59-s.html.

TARziU, A. M., \& VRABIE, C. I. (2016). NET Generation. Thinking outside the box by using online learning methods. New Trends and Issues Proceedings on Humanities and Social Sciences, 2(7), 41-47. DOI: 10.18844/gjhss.v2i7.1178

Yunus, M., Nordin, N., SAlehi, H., Sun, C. H. \& Embi, M. A. (2013). Pros and Cons of Using IICT in Teaching ESL Reading and Writing. International Education Studies, 6(7), 119-130. DOI: https:// www.learntechlib.org/p/161547/ 


\section{Authors}

PhDr. Krystyna Heinz, e-mail: heinzova@opf.slu.cz

She teaches at School of Business Administration in Karviná, Silesian University in Opava, Business English and courses related to Intercultural Communication designed for students of the Erasmus Programme and other international students, for example Culture Values in Business Communication, Personal Development Course for Mobility, Preparatory Course for Student Mobility, etc. She has been involved in several international projects focusing on developing intercultural competence in multicultural groups of students, the last one being the project ECMT+ in cooperation with 6 European universities in Belgium, Germany, Finland, France, Poland, Scotland - Entrepreneurial Communication in Multicultural Teams.

Mgr. Martina Chylková, e-mail: chylkova@opf.slu.cz

She teaches at School of Business Administration in Karviná, Silesian University in Opava, Business English and courses designed for Erasmus and international students, for example Intercultural Communication, Introduction to the Czech Language and Culture and Business Culture in Tourism designed for faculty students. She participates in teaching in some courses for students of the University of the Third Age. She has been interested in business communication in an international environment, she was involved in the project ECMT+ in cooperation with six European universities - Entrepreneurial Communication in Multicultural Teams - dealing with the dissemination of the outcomes of the project. 